is striking, and two recent studies of the long-term results have shown that $80 \%$ of cases have permanent relief. ${ }^{56}$ Though older patients and those with permanent changes do less well, the results do not seem to be influenced greatly by the age of the patient, the length of time symptoms have been present, or their severity. Quantitative evidence of the value of this treatment can be shown by follow-up nerve-conductiontime studies.

What happened to these patients before the condition was recognized ? Some were diagnosed as rheumatoid arthritis (often with justification); some as brachial neuritis ; many simply as acroparaesthesia. In many the condition subsided spontaneously, for it may be self-limiting and is prone to spontaneous relapse and remission. Tissue removed at operation in the recent studies ${ }^{56}$ shows in a high proportion of cases a chronic inflammatory synovial thickening in the carpal tunnel suggestive of a "rheumatic" process. This would explain the effects of hydrocortisone and the spontaneous remissions. The relationship to pregnancy and the menopause suggests that hormonal influences may also play a part indirectly. There are a number of different possible causes for a condition in which the common factor is compression and perhaps ischaemia of the median nerve, but the clinical picture remains constant and treatment by decompression is a simple, safe, and rewarding procedure.

Brain, W. R., Wright, A. D., and Wilkinson, M., Lancet, 1947, 1, 277 Garland, H., Bradshaw, J. P. P., and Clark, J. M. P., Brit. med. 7 $1957,1,730$

Thomas, P. K., Neurology (Minneap.), 1960, 10, 1045

Gilliatt, R. W., and Sears, T. A., f. Neurol. Neurosurg. Psychiat., 1958. 21, 109.

Phalen, G. S., f. Bone ft Surg., 1966, 48A, 211.

Cseuz, K. A. Thomas, J. E., Lambert, E. H., Love, J. G., and Lipscomb, P. R., Mayo Clin. Proc., 1966, 41, 232.

\section{Amines and Migraine}

Less than one year after its foundation ${ }^{1}$ the Migraine Trust has held its first scientific symposium on the condition. ${ }^{2}$ One of the main topics discussed was whether changes in the blood vessels occur during an attack of migraine, and if so how the changes are produced. Some workers ${ }^{3}{ }^{4}$ have doubted whether spasm of the cerebral arteries is a feature of migraine, even though this would explain many of the prodromal symptoms -such as visual scotoma or field loss, hemiplegia (either partial or complete), and ophthalmoplegia. Nevertheless, angiographic studies ${ }^{56}$ have now demonstrated the presence of vascular spasm beyond reasonable doubt, while preliminary studies of cerebral blood flow by inhalation of xenon-133 $133^{7-9}$ have also confirmed this. ${ }^{10}$

One feature that is frequently associated with the headache of migraine is vasodilatation, particularly of the extracranial vessels of the scalp. ${ }^{11}$ Though localized oedema and tenderness may be present, histological examination of a biopsy specimen of the temporal artery concerned has shown no evidence of inflammation ${ }^{12}$-a finding that strengthens the argument that vasoactive substances are implicated. Substances that have been considered for this role $^{13}$ include acetylcholine, substance $\mathrm{P}$, bradykinin and other kinins, histamine, serotonin (5-hydroxytryptamine), and noradrenaline.

Whether the polypeptides of plasma-the kinins and particularly bradykinin (formed by contact of plasma with glass)-will cause vascular headache directly or through potentiation by 5-hydroxytryptamine or some other painproducing substance is still being investigated, ${ }^{14}{ }^{15}$ for there is evidence both in favour of and against this suggestion. Thus, on the one hand an increased excretion of 5-hydroxyindoleacetic acid (derived from serotonin) and of vanilomandelic acid (derived from both adrenaline and noradrenaline) has been reported during attacks of migraine. ${ }^{16-19}$ Reserpine, which is known to deplete the tissues of 5-hydroxytryptamine and other amines, ${ }^{20}$ can induce headache in migrainous subjects, while methysergide-which is a strong serotonin antagonist-is effective in reducing the frequency of migraine in some patients. On the other hand, migraine does not occur in patients with carcinoid tumours, whose blood levels of 5-hydroxytryptamine are considerably raised, while conflicting results have been obtained by injecting 5-hydroxytryptamine into the subcutaneous tissue near the superficial temporal artery in an attempt to produce a migraine type of headache. ${ }^{21} 22$

Nevertheless, migraine has many other features besides the occurrence of a vascular type of headache. Nausea and vomiting, fluid retention followed by diuresis, changes of mood, and general and incapacitating malaise may accompany and occasionally overshadow the headache ; less commonly the prodromal stage of cerebral vasospasm may occur alone or with only a brief headache. Subjects with migraine may also have an increased frequency of reflex vasomotor abnormalities in the blood vessels of their hands. ${ }^{23}$

Migraine may have many trigger factors, which are of varying importance for the individual patient. What is still unknown, and requires much further research, is whether these trigger factors produce their effect through a common mechanism. One suggestion is that the hypothalamus may

Brit. med. F., 1966, 1, 1315

Ibid., 1966, 2, 1257 .

Pickering, G. W., Lancet, 1951, 2, 845.

- Denny-Brown, D., Med. clin. N. Amer., 1951, 35, 1457.

${ }^{5}$ Fletcher, T. M., Taveras, J. M., and Pool, J. L., Arch. Neurol. (Chic.), $1959,1,38$.

- Du Boulay, E. P. G. H., Acta radiol. (Diagn.), 1963, 1, 257.

'Mallett, B. L., and Veall, N., Clin. Sci., 1965, 29, 179.

Veall, N., and Mallett, B. L., ibid., 1966, 30, 363.

Jensen, K. B., et al., ibid., 1966, 30, 485.

O'Brien, M. D., and Veall, N., Proceedings of First Migraine Trust Symposium, 1967, in the press

1 Wolf, H. G., Headache and Other Head Pain, 2nd ed., 1963. Oxford University Press, London.

12 Adams, C. W. M., and Zilkha, K. J., Proceedings of First Migraine Trust Symposium, 1967. In the press.

is Ostfeld, A. M., The Common Headache Syndromes, 1962. Thomas,

14 Springfield, Illinois. Science, 1965, 4, 309 .

is Keele, C. A., and Armstrong, D., Substances Producing Pain and Itch 1964. Arnold, London.

16 Sicuteri, F., Testi, A., and Anselmi, B., Int. Arch. Allergy, 1961 19, 55.

17 Triangle (En.), 1963, 6, 116

18 Curran, D. A., Hinterberger, H., and Lance, J. W., Brain, 1965, 88 997.

19 Curzon, G., Theaker, P., and Phillips, B., 7. Neurol. Neurosurg. Psychiat., 1966, 29, 85.

20 Kimball, R. W., and Friedman, A. P., Recent Advances in Biological Psychiatry, ed. J. Wortis, 1961, 3, 200. Grune and Stratton, New York.

21 Ostfeld, A. M., 7. Amer. med. Ass., 1960, 174, 1188.

22 Kimball, R. W., Friedman, A. P., and Vallejo, E., Neurology (Minneap.), 1960, 10, 107.

23 Appenzeller, O., Davison, K., and Marshall, J., F. Neurol. Neurosurg Psychiat., 1963, 26, 447 . 
be the source of the final stimulus for the production of the abnormal vasomotor response. Research along these lines and into the metabolism of the amines and their effect on blood vessels may help in the further elucidation of this disabling condition.

\section{After the Freeze}

About two-thirds of the doctors in Britain work in the N.H.S. either as general practitioners or in the hospital service. Of the remainder, some are in the public health service, in the universities and medical schools, in industry, in the armed Forces, and in research. To attract doctors into these fields and to retain them in the face of competition their pay must be comparable to that offered to their colleagues of similar age and experience in the N.H.S. So the contracts offered to doctors outside the Health Service often contain an explicit or implied undertaking to maintain some sort of comparability with the Service, and when the pay scales in the Service are revised changes are made for the doctors outside it.

After the Review Body published its seventh report in April 1966 the B.M.A. put in claims for rises in pay for many of these groups. In some cases_-such as the medical teachers in universities and the doctors in the armed Forces-pay rises had been awarded to non-medical colleagues while the doctors had been told to await publication of the report before a claim could be considered. But on 20 July the freeze was announced. All negotiation stopped. Despite repeated requests, the Ministries and other employers concerned refused to commit themselves on their attitudes after the standstill.

The White Paper ${ }^{1}$ on the period of severe restraint, published on 22 November, has clarified the position for some doctors, but left doubts in the minds of many others. General practitioners are to get the full award of the Review Body from 1 April 1967, and hospital doctors will get their rises on 31 December this year, backdated to 1 October. Paragraph 34 of the White Paper sets out the principles that will govern negotiations that were in progress on 20 July:

“Where a commitment existed on or before 20 July 1966 io review pay with effect from a prior date, but the amount of any improvement had not been determined by 20 July, the operative date should be deferred by six months. Where, however, a commitment existed on or before 20 July to review pay with effect from a later date, but the amount of any improvement had not been determined by 20 July, the operative date should be deferred until at least 1 July 1967, except in so far as an earlier payment can be shown to be justified against the severe restraint criteria."

In the absence of the Chairman of Council, the Chairman of the Representative Body, Dr. A. N. Mathias, called a meeting on 23 November of the chairmen of the various B.M.A. Committees concerned in negotiations on terms of service with the Government. In the upshot it seems that doctors in the public health service, medical teachers and research workers, and doctors in the armed Forces can all show that commitments existed to award pay increases as from 1 April 1966, and so should be paid the increases from 1 October. Industrial medical officers have always faced the

\footnotetext{
- Prices and Incomes Standstill : Period of Severe Restraint, Cmnd. 3150 ,
} 1966. H.M.S.O. problem that each officer has his own contract, which varies from firm to firm. Many have clauses in these contracts specifying comparability with the scales awarded to hospital staff by the Review Body. So even though no commitment existed for the employer to agree a rise in pay from 1 April, there is a good basis for a claim to a rise before July 1967 in paragraph 30 of the White Paper, which states: "There may be exceptional circumstances in which some immediate improvement in pay is imperative to correct a gross anomaly."

Other discussions between Government departments and the B.M.A. were halted on 20 July. These included negotiations on professional fees for work undertaken for Government departments and local authorities. Here again negotiation can be resumed under the terms of the White Paper.

The Government has stated that it intends to "secure the effective and consistent application of the severe restraint criteria to claims and proposals to increase pay." It is indeed of the first importance that no injustice should be done to these groups of doctors, relatively small in numbers, working outside the Health Service, and the B.M.A., representing the whole profession, is taking action on their behalf.

\section{Congenital Dislocation of the Hip}

In spite of all that has been learnt in the past five or six years about congenital dislocation of the hip, the early diagnosis of it still remains the problem it was said to be in these columns in 1961. ${ }^{1}$ Many orthopaedic surgeons and paediatricians are now teaching the new ideas which came at the end of the 1950s from Italy and Scandinavia, notably from M. Ortolani ${ }^{2}$ and S. von Rosen. ${ }^{3}$ Diagnosis at birth was difficult until Ortolani demonstrated the simple technique of lifting a baby's hips in the flexed position and exerting a little traction in slight abduction with the examiner's hand. In cases of dislocation or subluxation the Ortolani " click" may be felt as the head of the femur slips in and out of the acetabulum. Early treatment of the babies in a simple splint that is changed once a week but which does not interfere with toilet arrangements is a great advance. Not only can the treatment be almost entirely in the mother's hands but it can be instituted at the time most likely to bring success.

Two simple types of splint are available-those of von Rosen and of T. G. Barlow. ${ }^{4}$ In addition to designing his splint Barlow carried out the largest survey ever done in Britain on the hips of newborn babies.

Working in Malmo, Sweden, von Rosen has also made some notable studies of the aetiology of the condition. Since the days of Hippocrates doctors have emphasized uterine pressure as a cause, and certainly every baby is subjected to a considerable amount of this. Doubtless it does play a part, but von Rosen has suggested one reason why the hips of some babies suffer more than others. It may be because of a greater transmission than usual of oestrogens through the placenta, which results in a consequent greater softening of the capsular

1 Brit. med. f., 1961, 1, 1746.

Ortolani, M., Pediatria (Napoli), 1937, 45, 129.

3 Rosen, S. von, Acta orthop. scand., 1956, 26, 136.

- Barlow, T. G., f. Bone fi Surg., 44B, 292.

Unpublished information.

Screening for Congenital Dislocation of the Hip, prepared by the Standing Medical Advisory Committee for the Central Health Services Council and the Minister of Health, 1966. Ministry of Health.

MacKenzie, I. G., Seddon, H. J., and Trevor, D., f. Bone ft Surg., $1960,42 \mathrm{~B}, 689$. 